\title{
Why might you use narrative methodology? A story about narrative
}

\author{
Lynn McAlpine ${ }^{\text {ab1 }}$ \\ ${ }^{a}$ University of Oxford \\ ${ }^{b}$ McGill University
}

\begin{abstract}
Narrative is one of many qualitative methodologies that can be brought to bear in collecting and analysing data and reporting results, though it is not as frequently used as say in case studies. This article provides a window into its use, from the perspective of a researcher who has used it consistently over the past decade to examine early career researcher experience - doctoral students, and those who have completed their degrees and are advancing their careers. This experience has contributed to a robust understanding of the potential of narrative, as well as its limitations. This paper first lays out the broad landscape of narrative research and then makes transparent the thinking, processes and procedures involved in the ten-year narrative study including the potential for creativity that narrative invites. The goal is to engage other researchers to consider exploring the use of narrative - if it aligns with their epistemological stance.
\end{abstract}

Keywords: qualitative methodology, narrative research, creativity

\section{Context}

Forty years ago, I was doing my doctorate and found myself alienated from the objectivist stance to research that was common in that time in education and, more generally, the social sciences. I struggled as an educator and junior researcher to find meaning in undertaking research in a way that seemed to me disconnected from experience, especially given its potential for intrusion, with minimal benefit, into the lives of research participants. Fortunately, I was in a university where narrative as a form of inquiry was just emerging as a fledging research approach, with a particular focus on how educators could use it to become more aware of, more reflective, and thus more intentional in their teaching practices. I found this approach intuitively

1 University of Oxford, Department of Education, 15 Norham Gardens Oxford OX2 6PY, United Kingdom; lynn.mcalpine@learning.ox.ac.uk 
and immediately powerful and was able to complete my dissertation in a way that was meaningful to me and, I hope, of some value to those who participated in the research. This past experience led to my lifelong interest in narrative (and reflection on experience) as features of my research stance, and is very evident in my most recent decade long qualitative, narrative research programme examining the lives of early career researchers. My hope is that I will intrigue readers enough to want to explore narrative further.

The italicised text above, stands in contrast to the abstract, though it achieves, I would argue, much the same purpose, to invite, you, the reader into the text. It is easily recognisable as a 'story', and embodies some of the key aspects of narrative as a research tool. It creates a construction of the 'self', me the narrator or protagonist, as an active agent. My story has a narrative arc; it demonstrates my goals and intentions, the ways in which I carried the action forward by making connections between events, shows the influence of the passage of time, and recounts the personal meaning of the experience (Coulter \& Smith, 2009). Nevertheless, like any story, there is much that is left out since it is a story told in a particular context (an article) to particular readers (I imagine you as interested in and knowledgeable about qualitative methods but unlikely to be as experienced with narrative as I am).

\section{Narrative as an everyday event}

Whether we have thought about it or not, narratives, whether oral or textual, are a distinct genre that we all know and use. In fact, we all tell stories about our lives every day since narrative provides a practical means for a person to construct a coherent plot about his/her life with a beginning, middle, end - a past, present and future. Each account, whether told only to oneself or to others, provides a robust way of integrating past experience into meaningful learning, locating oneself and others in the account, and foreshadowing the future.

Narratives incorporate temporality, a social context, complicating events, and an evaluative conclusion that together make a coherent story. Most important, the narrator or protagonist is an active agent not a dupe (Elliott, 2005) in the account. Thus, narratives provide a window into the process of identity construction (Riessman, 2008). Through the construction and recounting of narratives, individuals form and re-form who they have been, are presently and hope to become. Further, since narratives offer long-term reference points to replicate, live up to or overcome (Sfard \& Prusak, 2005), these stories can continue to influence how the narrator views him/herself and makes decisions to act (Holley \& Colyar, 2009). 
Lastly, narratives, when told to others, may also influence how others see the 'storyteller.'

I hope this framing of narrative as an everyday activity is helpful in thinking about narrative as a research methodology that we all are somewhat familiar with to some extent. In what follows, I offer to those perhaps not so familiar with narrative a sense of what I see as its potential as well as some of the cautions that, as with all research approaches, we need to be mindful of. I begin by providing context for why social scientists find it a useful methodology, then the varied methodological stances that are possible as well as the varied ways in which a narrative approach can be integrated into the research process. Building on this, I then describe, in quite concrete terms, how we have enacted a narrative approach in the last ten years, ending with ethical issues and narrative's benefits as well as limitations.

\section{Making sense of narrative as a research approach}

Narrative is one of many interpretive approaches in the social sciences though perhaps less well known than case study, ethnography, or grounded theor $y^{2}$. It has been used in sociology, organisational studies, gender studies, and education, and is closely linked to life history and biography, because like them it involves telling stories, recounting - accounting for how individuals make sense of events and actions in their lives with themselves as the agents of their lives.

Narrative researchers often find attractive and embrace the assumption that the 'story' is one, if not the fundamental, unit that accounts for human experience. In education, its use is perhaps best known through reflective studies of teachers' experiences (in fact the kind of study I engaged in for my doctoral study), in which the goal is to generate personal practical knowledge - "the teacher's past experience, in the teacher's present mind and body, and in the future plans and actions" (Connelly, Clandinin, \& He, 1997, p. 666). This form of inquiry was seen as a means to develop and value knowledge that had not always been valued in teacher education, one rooted in experience rather than research. In my field, higher education, while narrative has been taken up more recently than education, one can now find narrative being used, for instance, to study perceptions of academic and doctoral work. Regardless of the field, narrative research

2 While narrative methodology is largely used qualitatively, it can also be used in quantitative and mixed methods studies. For explanations and examples of these types of studies, see Elliott (2005). 
incorporates a range of methodological stances as well as ways in which data are conceived, collected, analysed and reported. I will introduce both of these perspectives before providing examples from published studies in higher education.

\section{Varied methodologies}

There are three main methodological stances (Elliott, 2005; Pinnegar \& Daynes, 2007). The second, a naturalist stance, best represents the one underlying our research.

- Sociocultural: The focus here is the broad cultural narratives that influence individual experience. This stance asks: What stories do people tell and use to participate in local practices? How are such stories cultural resources, that is, based in common narratives that individuals can call on and modify to better represent their own experiences?

- Naturalist: The focus here is rich descriptions of the content of people's stories about significant issues. So, data serve as a resource to ask: What experiences has this person had? What do these experiences mean to him or her? What complicating actions and evaluative aspects are highlighted?

- Literary: This approach, rarely used alone, is often integrated into either of the other two stances. The focus is the discourse that individuals use to describe their experiences: What images and metaphors (specific language) prevail in narratives that represent powerful influences on experience? What narrative arcs (actors, settings, plotlines), positive and negative, prevail in accounts?

\section{Varied research processes}

As in many methodological stances, a narrative lens can be integrated into the research process throughout the design or only at various points.

- Collection and conception of data: Many studies using narrative depend on oral accounts, i.e., interviews which are then transcribed, but studies may also collect data in textual form, e.g., unstructured diaries, semistructured activity logs. Further, such data may or may not be conceived as narratives in their own right, i.e., coherent stories of how participants account for what has happened to them. Yet, this does not preclude using narrative in later steps of the research process. For instance, Churchman \& King (2009) used comments on flip chart sheets tracking the discussion at a world café event (clearly not narratives) to make vignettes of workplace experience (data analysis) which they used to generate results. 
- Data analysis: Regardless of the methodological stance in any narrative study, if narrative analysis is used, the goal is to understand in the first instance the chronological arc of meaning in an individual's experience - whether or not the ultimate goal is to preserve an idiosyncratic account of experience (naturalistic) or seek shared cultural narratives (sociocultural) or powerful metaphors and language that define experience (literary). The goal of analysis is therefore "keeping a story intact by theorising from the case rather than from component themes across cases" (Riessman, 2008, p. 53). This approach contrasts with thematic analysis in many other research traditions where findings are analysed and organised first by theme rather than by individual (see Miles \& Huberman, 1994). Of course, participant narratives can also be analysed using more traditional approaches such as thematic analysis.

- Data reporting: Not all narrative-based studies use researcher constructed narrative accounts to report the results of analysis, but those who do will usually invoke literary elements in constructing low inference accounts that represent participant experience, e.g., plot; characters which help the plot unfold; and the point of view through which the story is told - 1st or 3rd person (Holley \& Colyar, 2009). Whether or not researchers create narrative cameos or vignettes in reporting their research, many will use other means of reporting that draw on more traditional forms of thematic analysis, e.g., summaries of themes often accompanied by interview excerpts. Of course, many studies which are not narrative based may also use narrative elements in reporting the results.

In our research, we conceive data as participant narratives, engage in narrative analysis using a naturalist approach followed by thematic analysis across cases, and use both cameos and themes in our reporting.

The following descriptions provide, I hope, concrete examples of the three stances and how a narrative lens was brought to bear in the research process (underline).

- Sociocultural: Ylijoki (2001) studied the relationship between the student and supervisor and the problems encountered in the Master's thesiswriting process. Her starting point was that prevailing cultural stories about the process provide individuals with resources to conceive their own experience. She wanted to discover what these cultural accounts were. She drew on 72 interviews (individual and focus groups) with Master's students across four disciplines at different points in their degrees. She did not conceive these interviews as narratives since the student reports moved back and forth in time and themes. But she used narrative analysis to create coherence and temporal order in students' 
descriptions of the thesis writing process. In doing so, she sought commonalities in the data to construct four prevailing 'ideal-type' accounts. These four ideal-types were distributed evenly across students at all stages of thesis-writing. Each ideal-type had a different plot structure, storyline, and role for the protagonist, the student (some literary analysis). She did not use researcher constructed narratives to represent each ideal-type but rather described their nature and the differences among them. She argued that students would draw on and modify these idealtypes in conceiving their own thesis-writing process.

- Naturalist: Cumming (2009) conducted a narrative case study of one science doctoral student to demonstrate that the normative assumptions, what he termed the orthodox model, about science doctoral education hide important variability. He wanted to examine what he called the micro-worlds of those involved in the doctorate. His goal was to document the particularity and intricacy associated with one science student's doctoral experience by integrating a series of interviews (transcripts as narratives) with her, as well as interviews with her co-supervisors. From these data, he then created a stand-alone narrative case (researcher constructed narrative) which he called polyvocal since it synthesised the student's experiences in relation to her co-supervisors, devoid of specific commentary by him. This was followed by his narrative interpretation: his views on how her narrative was distinct in a number of ways from the orthodox model. He noted in particular how the narrative made clear the student's agency while also being supported by her supervisors. (This study is representative of many naturalist narrative studies in examining one case, though it is unusual in having integrated perspectives from others.)

- Literary: Hopwood and Paulson (2012) began with the premise that in examining doctoral experience bodies have been ignored and minds privileged, and argued the need to take bodies seriously. They undertook to demonstrate the multiplicity of bodily experiences and how meaningful and significant bodies were in doctoral experience by looking at the language students employed. They drew on what they considered student narratives - both verbal (interviews) and written (weekly logs) - from 33 social science doctoral students. Using a form of discourse analysis they drew out examples of how language defined and described bodies (e.g., gender, pregnancy, race, youth/age, fitness, abnormal bodies, e.g., dyslexia) and related emotions (e.g., crying, adrenalin, collapse, froze, dance around the house, sick, puking, anxious, rage, frustrated). The report of their results was thematic and no researcher constructed narratives were 
offered. Rather, they used interview excerpts to exemplify the presence of bodies. They concluded that living through a doctorate is an inescapable bodily experience.

\section{How narrative research frames our thinking and actions}

\section{Research context}

Initially, our motivation for this research was quite pragmatic: to address the substantial and pressing problem of $\mathrm{PhD}$ non-completion. About a year into the research, we changed our initial focus on non-completion to one that highlighted learning to do academic work, so following participants after the degree. And, as we saw individuals taking up a range of careers, we became interested in documenting each individual's unique trajectory qualitatively from $\mathrm{PhD}$ studies into a range of careers - with particular interest in understanding the role played by intention and resilience in crafting a post-PhD career (McAlpine, 2014; McAlpine, Amundsen, \& Turner, 2014). Thus, over a decade, we have used a naturalist narrative approach longitudinally to follow more than 100 scientists and social scientists originally in Canada or the UK for at least 18 months, and 48 for periods of 4-6 years. What makes our research distinct from most naturalist narrative studies is the longitudinal approach and the multiple individuals we have followed given most studies examine one or a few individuals only at one point in time. (For a fuller explanation of both our epistemological and methodological approach, please see McAlpine, Amundsen, \& Turner, 2013).

Our epistemological stance in this work could be described as critical realist (Archer, 2003). Thus, we are interested in how individuals, through their actions, exercise agency in ways that include efforts to avoid, challenge or resist perceived practices and policies. And, like others, we make little distinction between thinking, learning, and the formation of identity (Billett \& Somerville, 2004). We found a naturalist narrative methodological stance aligned well with this epistemology since we were particularly interested in documenting and understanding the distinctiveness of each trajectory. We came to view the work we were doing as tracking individuals' identity development, conceiving identity as incorporating the permanence of an individual's perception of unique identity combined with a sense of personal change rather than stability through time (Riessman, 2008). Since we began this research, we have published around 50 peer-reviewed papers. Most of these represent the use of narrative research longitudinally which is relatively rare (e.g., McAlpine, in press), but a few represent the 
more common approach of one-time data collection (e.g., McAlpine, 2016). Below, I summarise each of these two studies in the same way as the three examples provided earlier.

\section{Two examples}

Using a longitudinal approach, McAlpine (in press) examined the career decision making processes of eight social scientists who went into non-academic careers, following them from the beginning, during their degrees, and into their initial years after graduation. The goal was to understand their career decision making processes since more than half of $\mathrm{PhD}$ graduates leave the academy, but little is known of how they end up in the positions they find. Four forms of narrative data (explained in more detail shortly) were collected over a 12 to 18 month cycle and the cycle repeated at least three times. The multiple narratives provided different ways to understand the career intentions, decision making and chronology of each individual's experiences. The narratives for each individual were re-read iteratively to construct a case summary which captured how each individual imagined a post- $\mathrm{PhD}$ career during the degree, and perhaps changed career intentions over time. This approach to analysis, as noted earlier, is common in narrative research. Once the eight case summaries were constructed, these provided the basis for a cross-case analysis seeking patterns. The analysis highlighted variations in clarity of career vision, and strategic career thinking and action. The results, presented as both cameos and themes with interview excerpts, made clear that post-PhD career trajectories are best built from the beginning of the $\mathrm{PhD}$, a conclusion with curriculum implications.

McAlpine (2016) examined the journey from $\mathrm{PhD}$ graduation to first grant as Principal Investigator (PI) since achieving research independence is a key contributor to academic permanence. The narrative-based study documented how 16 scientists in three universities worked towards the aspired role and then dealt with achieving this aspiration. During an interview the participant narrated the highs and lows of the journey from $\mathrm{PhD}$ to first PI grant. This narrative was supplemented by two other forms of narrative: a drawing of the journey by the participant, and a CV (an academic narrative). The combination of visual and dialogic information provided different means of understanding the intentions, high and low events, and a chronology of their experiences. The same approach to analysis was used as in McAlpine (in press), creating case summaries of each individual's experience before looking across cases for patterns. The 
results highlighted the centrality of emotion in the often lengthy journey to PI-status - a journey that required resilience and self-belief as individuals navigated their intentions in a sustained fashion to achieve funding essential for advancing their careers.

\section{How we use narrative}

Perhaps what is most important to us about narrative research is the potential it provides to value multiple ways of knowing (Pinnegar \& Daynes, 2007). Using a narrative methodology, particularly longitudinally with a relatively large number of individuals, enables us to document variable and shifting ways of understanding experience, both within and between individuals. Finally, since multiple views on experience can co-exist as part of the narrative research report, we would argue it is possible to provide a richer and more plausible representation of lived experience. I turn now to the specifics of our approach to narrative data collection, analysis, construction and display.

\section{Narrative in data collection}

In common with many other interpretivist researchers (Creswell, 2007), we view data collection as a negotiated interaction (Taylor, 2008), a coconstruction between researcher and participant (Sfard \& Prusak, 2005), with both jointly responsible for the stories that emerge. These narratives represent accounts of participants' lives that are already 'edited' as they emerge - that -is, reduced by location, time, format, and interlocutor - for a specific research purpose at our request.

We use semi-structured interviews as one means to derive narratives, while mindful that interviews tend to draw forth only what has overall salience at the interview time - and we might miss forgotten critical events and shifts in experience through time. Thus, we sought to collect narrative about the day-to-day experiences influencing individual's engagement in academic-doctoral work, as well as the successes and challenges impacting their long-term progress. This led us to collect electronic semi-structured weekly activity logs. We also decided as time went by to collect two other electronic forms of narrative, a biographic questionnaire, and a pre-interview questionnaire ${ }^{3}$. They are described below in the order in which they occur in a 12 to 18 month cycle, which is then repeated.

3 New technologies have made it increasingly more straightforward to collect, store and analyse multiple forms of data. 


\section{Biographic questionnaire}

This is completed as the first step in the cycle of data collection, and provides basic information about the individual's past, present and intended future, e.g., present role/status, updates on scholarly publications and presentations, changes in specialism, etc.

\section{Weekly activity logs}

The logs are collected on a regular basis (every 4-6 weeks), and are structured to seek participant narratives about day-to-day experiences in a specific week. They combined short-answer questions (often including 'why' to capture the meaning of the experience), completion items as well as lists to choose from. Participants provide information about how much time they spent on work during the week, what activities they engaged in, who they interacted with, significant individuals and experiences and why these were significant, difficulties and how they might be overcome, etc. (Recently, we did an analysis to see if the logs actually provided us with different accounts of experiences than interviews, and found they did (McAlpine \& Amundsen, 2015). Individuals have also reported that completing them was personally useful in giving them a sense of progress over time (Alexander, Harris-Huemmert, \& McAlpine, 2014). (See Appendix 1 for a sample completed $\log$ (response edited to reduce the length) and the kinds of narrative that such a structure provides.)

\section{Pre-interview questionnaire}

In contrast to the logs, the pre-interview questionnaire is designed to capture broader perspectives as well as some retrospection on the past year. It is sent to participants after about 10 months shortly before they are to be interviewed. They are asked to comment on what they see as significant events or achievements and to update us on any other changes in the past year. The purpose is to capture anything salient to them that we may not have learned through the logs.

\section{Interview}

In preparation for the interview, the researcher re-reads all the narratives provided by the participant in order to generate questions related to different parts of the interview; we attempt to have the same interviewer each year though this is not always feasible. The interview begins with a 
series of general questions related to the previous year's interview as well as points of interest in the pre-interview questionnaire. Second is a section in which individuals are asked to elaborate on some of the experiences they described in the logs that are viewed by us as pertinent. The third section varies by year (see next paragraph). In the last section, individuals are asked about their perspectives and hopes for the future, both in one and five years.

\section{Interviews supplemented by visual methods}

We have also integrated visual methods in our interviews since visual methods can capture a less inhibited, more spontaneous account of experience (Bagnoli, 2009). Still, a verbal or written interpretation of the participant's work is critical in aiding the researcher's analysis (Buckingham, 2009). For instance:

- We used journey plots in the McAlpine (2016) study. We were particularly interested in the emotional responses to trying to gain PI status. So, we asked individuals to draw a journey plot at the beginning of the interview. The horizontal axis represented time from $\mathrm{PhD}$ graduation to getting their first PI grant, and the vertical axis the emotional highs and low of the journey. Individuals completed the task very quickly - often in less than a couple of minutes - proof that it captured a quite spontaneous view of experience. We concluded that the task was intuitively meaningful and it was 'editable' as the interview progressed and other key incidents emerged. (See Appendix 2 for a sample completed journey plot from that study.)

- We have also used cards within an interview in our longitudinal research. For instance, to concretely capture the connections individuals experienced among a) personal relationships, b) work activities, and c) emotions, we asked interviewees to physically place relevant cards in relationship to each other while describing the nature of the interaction - and add any new cards they wished. At the end of the interview, the result was photographed. Overall, we have concluded that the range of strategies available to us as researchers in collecting narratives are quite numerous and that the possibilities are in some ways only limited by our imagination.

While our protocols have remained relatively consistent in structure over repeating cycles of data collection, we have made small modifications to them based on emerging findings, and to member check themes and issues that emerge. Further, while there is consistency in the type of information requested across the roles (doctoral student, post-PhD academic 
or post- $\mathrm{PhD}$ professional), the choices and wording on each protocol vary somewhat to be suitable for the particular role. These different versions are sent, completed and returned electronically which facilitates participation by individuals geographically distant, but also means that we cannot mediate individuals' responses as the complete the written narratives in the same way we can interviews.

\section{Narrative and data display in analysis}

Given our naturalist stance, we focus on the idiosyncratic features of an individual's personal accounts (rather than the shared ones in a sociocultural stance). Our goal is to understand this individual's experiences and how she/he interprets them as regards the achievement (or not) of personal intentions. It is here perhaps that one sees most concretely how narrative is different from other qualitative methods. Still, the guiding principle, as in many other qualitative approaches, is analysis-in-context to acknowledge the larger circumstances in which each narrative was constructed (Juzwik, 2006). So, for instance, we will be attentive to the historical period, in our case, before or after the economic crisis; the geographical location, Canada, the UK, Europe; the context for the data collection.

Our first step in analysis is to construct for each participant a case narrative which we view as a form of data display (Miles \& Huberman, 1994) which can be used in further analyses. We re-read all the data for each individual (narrative analysis) in order to create a comprehensive, low-inference narrative that preserves the individual's voice (Coulter \& Smith, 2009). In other words, we retell in reduced form (often using short direct quotes) the participant's experiences (Sfard \& Prusak, 2005) while retaining the elements of narrative: connections between events, the passage of time, and individual intentions. Our overall goal in this process is to preserve as best as possible the individual's story without our interpretation intervening while, at the same time, becoming familiar with each individual case. (In the longitudinal research, these case summaries are completed annually.)

Once all the individual analyses leading to case summaries have been completed, we engage in a second level of analysis. It is at this point that our own interpretation of these accounts is brought to bear. We do this by seeking similarities and differences in patterns across individuals to examine in more depth. This secondary level of analysis would have less potential with fewer participants since the greater the number of participants the greater the potential for more variability in the meaning of experience, as well as patterns of shared meanings. As in other approaches to 
qualitative analysis, at this point we employ emerging (and sometimes $a$ priori) coding schemes and include constant comparison and negative case analysis with attendant procedures to establish trustworthiness (Miles \& Huberman, 1994). When possible, we engage other members of the team in different stages of the process.

\section{Narrative construction and display in reporting}

As noted earlier, in doing narrative research we want to ensure we preserve the focus on the individual not just in analysis but also in how we report the findings. Thus, we have spent considerable time developing different and creative ways of re-presenting, re-constructing, participant narratives in ways that will preserve their individuality in our reporting while making shared patterns of experience evident. The challenge is how to preserve the fullness and complexity of people's lives in reports often limited to 5000-7000 words. So, in contrast with other qualitative methods, we develop cameos to preserve the complexity of the individual's experience. Such cameos vary in length from 100-350 words (see Appendix 3, Example 1 for a cameo used in a paper). When possible, we include in the paper all cameos relevant to the analysis, but if this is not possible, then we choose exemplars. Further, since our second level of analysis involves seeking patterns across individuals, when we want to highlight such patterns we have used formatting to make it easier for the reader to see the patterns (see Appendix 3, Example 2 for an example of three cameos in which career decision making is similar; it was included in McAlpine, in press).

We hardly ever use participant quotes alone in reporting results since this would create a disembodied voice losing the personal context and meaning in which the statement was made. Instead, if we use a quote it is often embedded in a brief summary or whenever possible excerpted from the data provided by an individual already cameoed in the paper. In common with other interpretivist researchers, our hope it that reports of our research achieve fidelity, coherence, plausibility, usefulness, authenticity, trustworthiness, resonance (Coulter \& Smith, 2009; Pinnegar \& Daynes, 2007).

\section{Ethical concerns}

We are mindful of the need to be cautious in constructing cameos for reporting results since their very length forces us to leave out much. Further, we want to avoid imputing meaning that wasn't in the original 
narratives as we blend diverse experiences into relatively coherent narratives meaningful to readers.

In our longitudinal research, there are a number of ethical challenges that are less likely to arise in one-time studies. We aim to bring an ethic of care to our relationship with participants (Tronto, 1995), since over time we develop a privileged intimate knowledge of an individual - as one participant said "you know my life." Perhaps the most striking example of this ethic of care is that we read the weekly activity logs as soon as they come in, watching for any signs of ongoing distress. In such cases, the local team generates suggestions of useful resources to the participants, e.g., reference to institutional counselling or relevant policy. As well, in e-mail communication, we will often refer to recent events or experiences they have reported.

In common with other qualitative researchers, we take care in reporting results to ensure anonymity. As a team, we have developed agreements as to how to remove personal details that we believe may reveal identity, e.g., use 'partner' instead of 'husband'/'wife', refer to 'child'/'children' instead of 'son'/'daughter', use only country or continent as a geographic location, etc.

For the longitudinal research, this is particularly important since reporting the idiosyncratic chronology of an individual's life over a number of years makes recognition somewhat easier. The challenge of preserving anonymity can be exacerbated if growing intimacy in the relationship over time leads to accounts that might not otherwise be revealed. Individuals have the right to remove excerpts if they wish - though this has rarely happened. Evidently, removal of information raises challenges in doing justice to the actual accounts while preserving anonymity. Beyond that which is noted in the previous paragraph, we may change details of an individual's account while preserving the essence of the experience.

In addition to removing personal details in reports, in the longitudinal research we also construct two page low-inference summaries of each individual's narratives as they complete their participation in research. We send these to each participant with the following request:

We would like your help to ensure we have got it right. Could you please review the summary and tell us if there is anything you feel a) is left out, b) is wrong, or c) could reveal your identity.

We have been pleased that on the whole there have been very few edits to these accounts so we believe we have found a relatively robust way of ensuring anonymity. 


\section{Advantages and disadvantages of using narrative}

Narratives are inherently and explicitly agentive and demonstrate how individuals attempt to navigate their desires, hopes and intentions within the vagaries of the structural features of their lives as well as the unexpected. In my field as in some other social sciences, there has been a privileging of a systemic or structural perspective stressing how the organisation and society directs individuals' learning and development (Antony, 2002). This has meant that individual efforts to be self-motivated and agentive tend to be underplayed and individual variation lost. A narrative stance can complement a structural stance by providing an alternate view. As Elliott (2005, p. 125) notes: narratives "avoid the extremes of both essentialist and constructivist views of self." A further advantage is that researcherconstructed narratives are easily accessible to readers, so the results of the research can be used pedagogically to offer alternative futures, in my case, to doctoral students as they imagine their futures.

Still, as with all methodologies, there are limitations. We are mindful that identity construction as represented in narrative is only one aspect of identity-as-action. It stands in, as it were, for engagement in practice and it is important to avoid the reification of identity (someone 'is an identity') and instead emphasise someone 'acting an identity' (Sfard \& Prusak, 2005).

As well, the inherent structure of narratives (an active agent constructing a coherent account of experience) means that narratives "often speak in ways that overlook any overarching sense of indeterminacy, partiality and complexity" (Taylor, 2008, p. 29). Further, participant narratives capture only a limited number of experiences, which we then, as researchers, use to approximate a coherent story. Thus, the researcher needs to be mindful of what is left out of an individual's accounts, as well as inconsistencies across accounts, or the meaning of hesitations or hedging in the accounts. (Of course, the larger the number of research participants, the more varied the representation of experience will be and the more the researcher can feel $\mathrm{s} /$ he has captured a range of experiences and meanings.) Lastly, narratives tend to focus on 'close to home' interpretations of experience and may ignore broader structural influences (Walker, 2001). To address this issue, Elliott (2005) suggests researchers seek out large pertinent data-bases, e.g. census data, as a means to contextualise the accounts. 


\section{Value of narrative as a methodology}

My goal, which I hope I have achieved, was to make more transparent the thinking, processes and procedures involved in using narrative methodology, in my case from a naturalist stance, and through this to intrigue others to want to explore the use of narrative. Narrative remains, as Pinnegar \& Daynes (2007, p. 28) note, on the "margins of academic work." Still, it offers sound methodological tools to the researcher who seeks to pay closer attention to the diversity of human experience and finds a good alignment between his/her epistemological stance and the range of methodological stances on offer in narrative research.

\section{References}

Alexander, P., Harris-Huemmert, S., \& McAlpine, L. (2014). Tools for reflection on the academic identities of doctoral students. International Journal for Academic Development, 19(3), 62-173. doi: http://dx.doi.org/10.1080/1360144X.2013.817333

Antony, J. S. (2002). Reexamining doctoral student socialization and professional development: Moving beyond congruence and assimilation orientation. In J. C. Smart (Ed.), Higher education: Handbook of theory and research (Vol. 17, pp. 349-380). Dordrecht: Kluwer. doi: http://dx.doi.org/10.1007/978-94-010-0245-5_8

Archer, M. S. (2003). Structure, agency and the internal conversation. Cambridge: Cambridge University Press. doi: http://dx.doi.org/10.1017/СBO9781139087315

Bagnoli, A. (2009). Beyond the standard interview: The use of graphic elicitation and arts-based methods. Qualitative Research, 9(5), 547-570.

doi: http://dx.doi.org/10.1177/1468794109343625

Billet, S., \& Somerville, M. (2004). Transformations at work: Identity and learning. Studies in Continuing Education, 26(2), 309-326. doi: http://dx.doi.org/10.1080/158037042000225272

Buckingham, D. (2009). „Creative” visual methods in media research: Possibilities, problems and proposals. Media Culture Society, 31(4), 633-652. doi: http://dx.doi.org/10.1177/0163443709335280

Churchman, D., \& King, S. (2009). Academic practice in transition: Hidden stories of academic identities. Teaching in Higher Education, 14(5), 507-516. doi: http://dx.doi.org/10.1080/13562510903186675

Connelly, F. M., Clandinin, D. J., \& He, M. F. (1997). Teachers' personal practical knowledge on the professional knowledge landscape. Teaching and Teacher Education, 13(7), 665-674. doi: http://dx.doi.org/10.1016/S0742-051X(97)00014-0

Coulter, C. A., \& Smith, M. L. (2009). The construction zone: Literary elements in narrative research. Educational Researcher, 38(8), 577-590.

doi: http://dx.doi.org/10.3102/0013189X09353787

Creswell, J. W. (2007). Qualitative inquiry and research design: Choosing among five approaches (2nd ed.). Thousand Oaks, CA: Sage. 
Cumming, J. (2009). The doctoral experience in science: Challenging the current orthodoxy. British Educational Research Journal, 35(6), 877-890.

doi: http://dx.doi.org/10.1080/01411920902834191

Elliott, J. (2005). Using narrative in social research: Qualitative and quantitative approaches. London: Sage.

Holley, K. A., \& Colyar, J. (2009). Rethinking texts: Narrative and the construction of qualitative research. Educational Researcher, 38(9), 680-686. doi: http://dx.doi.org/10.3102/0013189X09351979

Hopwood, N., \& Paulson, J. (2012). Bodies in narratives of doctoral students' learning and experience. Studies in Higher Education, 37(6), 667-681. doi: http://dx.doi.org/10.1080/03075079.2010.537320

Juzwik, M. (2006). Situating narrative-minded research: A commentary on Anna Sfard and Anna Prusak's „Telling identities”. Educational Researcher, 35(9), 13-21. doi: http://dx.doi.org/10.3102/0013189X035009013

McAlpine, L. (2014). Post-PhD trajectories: Desperately seeking careers? Higher Education Review, 47(1), 4-35.

McAlpine, L. (2016). Becoming a PI: Shifting from „doing” to „managing” research. Teaching in Higher Education, 21(1), 49-63. doi: http://dx.doi.org/10.1080/13562517.2015.1110789

McAlpine, L. (in press). Post-PhD non-academic careers: Intentions during and after degree. International Journal for Researcher Development.

McAlpine, L., \& Amundsen, C. (2015). Early career researcher challenges: Substantive and methods-based insights. Studies in Continuing Education, 37(1), 1-17. doi: http://dx.doi.org/10.1080/0158037X.2014.967344

McAlpine, L., Amundsen, C., \& Turner, G. (2013). Tracking experience over time: Epistemological issues and methodological challenges. In J. Huisman \& M. Tight (Eds.), Theory and Method in Higher Education Research (pp. 97-114). London: Routledge. doi: http://dx.doi.org/10.1108/S1479-3628(2013)0000009009

McAlpine, L., Amundsen, C., \& Turner, G. (2014). Identity-trajectory: Reframing early career academic experience. British Educational Research Journal, 40(6), 952-969. doi: http://dx.doi.org/10.1002/berj.3123

Miles, M. B., \& Huberman, A. M. (1994). Qualitative data analysis (2nd ed.). Thousand Oaks, CA: Sage Publications.

Pinnegar, S., \& Daynes, J. G. (2007). Locating narrative inquiry historically: Thematics in the turn to narrative. In D. J. Clandinin (Ed.), Handbook of narrative inquiry: Mapping a methodology (pp. 1-34). Thousands Oaks, CA: Sage. doi: http://dx.doi.org/10.4135/9781452226552.n1

Riessman, C. K. (2008). Narrative methods for the human sciences. Los Angeles, CA: Sage.

Sfard, A., \& Prusak, A. (2005). Telling identities: In search of an analytic tool for investigating learning as a culturally shaped activity. Educational Researcher, 34(4), 14-22. doi: http://dx.doi.org/10.3102/0013189X034004014

Taylor, P. (2008) Being an academic today. In R. Barnett \& R. Di Napoli (Eds.), Changing identities in higher education: Voicing perspectives (pp. 27-39). London: Routledge. 
Tronto, J. C. (1995). Care as a basis for radical political judgments. Hypatia, 10(2), 141-149. doi: http://dx.doi.org/10.1111/j.1527-2001.1995.tb01376.x

Walker, M. (2001) Engineering identities. British Journal of Sociology of Education, 22(1), 75-89. doi: http://dx.doi.org/10.1080/01425690020030792

Ylijoki, O.-H. (2001). Master's thesis writing from a narrative approach. Studies in Higher Education, 26(1), 21-34.

doi: http://dx.doi.org/10.1080/03075070020030698 


\section{Appendix 1. Sample completed log}

Below is a transcription of a weekly log collected from a PhD science student. Student's responses to questions are presented in italics with some edits to preserve anonymity and reduce the length.

1. This week, I spent approximately _40_hours on academic work that ultimately contributes to my doctorate.

2. Please note the different activities that contributed to this investment of time. (Mark an X to the left of all that apply and provide details.)

a) X Reading ____I spent a lot of time reading web pages about LaTeX, an opensource document-preparation system, while learning to use it to write my first thesis chapter / publication

b) Literature review

c) Obtaining ethics approval

d) Preparing for comprehensive exam

e) Preparing for research proposal

f) Fieldwork preparation

g) X Data collection____ I spent most of my time this week processing samples in a gas chromatograph to collect data from them. I processed about 80 samples this week.

h) X Data analysis ____While waiting for the gas chromatograph to process each sample, I also spent time organising data files, and writing analysis scripts to process the data once it is available.

i) Writing up thesis

j) X Writing for publication/ conference/reports _____I wrote the bulk of the methods section for a publication, which will also be a chapter in my thesis.

k) Presented research at conference/ workshop/ seminar (where and on what topic?)

l) Attended a conference/ seminar/ workshop (where and on what topic?)

m) X Meeting/ speaking/ corresponding with supervisor(s)____I had a 1 hour weekly meeting with my supervisor to discuss progress and deadlines. He had asked for a methods section by this week, which I achieved most of. My priority is still to finish data collection, so I can get results and begin formulating the rest of the paper.

n) Meeting/ speaking/ corresponding with other academics

o) X Other (please specify e.g. funding applications):

I spent about an hour looking into a conference I'd like to attend ... and investigating costs, preparing a budget, and funding options. I have a couple of travel grant applications to fill out over the next couple of weeks, but I don't need to do that right now.

3. This week I also

a) Worked full time in non-academic work

b) $X$ Worked part time in non-academic work 4h: Organising committee work \& meeting for a Science-Policy Conference to be held [here]. 
c) X Worked part time on research not related to my doctorate (if so, who or what was this for?) _____ I spent a couple of hours organising and EndNote database for a contract job. It is the last task for which I am responsible for the project, so I'm trying to get it "off my plate", although the topic is directly relevant to my research, even if the task itself does not contribute directly to my thesis.

d) Worked as a teacher, tutor, or instructor (if so, please specify what and where)

e) Attended an academic committee meeting (if so, what committee was this?)

f) X Attended workshops, classes, seminars, or lectures (if so, where and what topic?) _____: statistics workshop

g) Acted as a caregiver (for children, spouse, other relatives etc.)

h) Other (please list any you think are important, e.g., sport/leisure activities, voluntary work, socialising, travel etc.)

4. Please add any comments/elaborations relating to how you spent your time this week.

Although I spend most of my time at a gas chromatograph putting in samples, the nice thing is that I have 7 minutes to wait in between each sample. I typically set up my laptop beside the GC to do other work while waiting for the GC. It means the samples take a little longer than they need to (I occasionally get distracted and wait longer than necessary between samples), but also means the work is less boring and I get a lot more done. Or at least, I feel like I do.

5. This week I engaged with the following people to help me with my doctoral work.

a) X Student in my research group/team____I e-mailed technical questions about LaTeX to some colleagues in my lab who have also used it.

b) Another student(s) (if so, where were they from?)

c) XMy supervisor____We had a meeting this week to discuss progress and deadlines.

d) Program director

e) Other professors (if so, where were they from?)

f) Library staff

g) X Other University staff (e.g., secretaries, careers, computing services) (please specify) I asked some computer staff about backup options, and also co-ordinated with technical support staff for installation of software on lab computers, for microscope cameras.

h) Family

i) Friends

j) Other (Please specify)

6. This week with regard to my supervisor(s) I feel that I . (Please mark an X to the left of the ONE response that best fits your experience this week.)

a) X didn't need any help I already knew what I had to do, and just needed uninterrupted time to do it. Although we did have a meeting, we talked in the lab next to the gas chromatograph, so I could continue to process samples during the same time without having to significantly interrupt my research activities.

b) needed help 
c) didn't want any help

d) wanted help

IF you wanted or needed help from your supervisor, please answer the next question; if not, please go to question 8 .

7. If you wanted or needed help, what was your concern?

a) Why did you feel your supervisor was the best person to help?

b) Did you get the help you needed?

c) If 'no' please explain why you think this was the case.

d) Did you get the help you needed from someone other than your supervisor? Who was that person(s)?

8. This week the most significant individual(s) to my academic progress (whether positively or negatively) was

a) The internet: I did a lot of research on LaTeX online. My lab work was largely independent.

b) They were significant because Online content published by other academics provided me with specific information I wanted, and helped me solve problems and make progress on my goals!

9. If there was a significant event or experience in which you felt like an academic or felt that you belonged to an academic community, please tell us about it. felt like an academic the whole time I was in the lab, and especially while learning to use an arcane (but effective!) document preparation system for technical writing (LaTeX). Beginning the writing process was also important, because it is usually the most difficult. [DELETED TEXT]

Why was this event or experience important? Seeing the product helps me feel a sense of accomplishment, no matter how small. I was also reminded how much I can enjoy writing, and was a little surprised by how motivated I was to continue writing late into some nights, once I got over the initial overwhelming feeling of starting. [DELETED TEXT]

10. If there was a significant event or experience in which you did not feel like an academic or felt that you were excluded from or not part of an academic community, please tell us about it. At the start of the meeting I described in the previous question, I did feel excluded from the academic community by some of the other people at the meeting, who seemed to refer to the "resources" of the department and other institutions and the "needs" of students. I quickly pointed out that I felt this was a nonsensical division and pointed out how much graduate students can actually contribute to peer-learning. [DELETED TEXT]

Why did this experience make you feel this way?

11. What things, if any, do you feel you should have or wanted to focus on this week but couldn't?

a) Why was this? 
12. Please indicate any difficulties you encountered this week.

The sample processing I am doing seems to take longer than I had planned. Most things do. Each sample requires a minimum of 8 minutes of total time, yet it is difficult to stay productive, and put samples in at a fast enough rate, to get enough done in a day for me to feel productive. I like to set daily goals, but to meet them, I sometimes have to stay until very late in the lab, and this interferes with my eating \& sleeping schedule, which makes me feel crummy and cranky. Until the weekend, when I start to feel more satisfied with my overall progress. I also started to learn a new system for writing scientific manuscripts (LaTeX). I am familiar with the general approach, but not the specific details needed to accomplish what I want.

a) What did you do to try and overcome them? I do lots of cooking on the weekend, so I have more leftovers during the week, which lets me spend more time in the lab, since I need less time at home.

I overcame my learning needs by searching and reading online content.

13. To what extent do you feel you are able to achieve work-life balance? What challenges and/or strategies contribute to this balance (or lack thereof)? I would say relatively low work-life balance this week, as most of my time was spent working. This is largely due to deadlines approaching, and much work left to do to achieve them. I think this is partly due to too much time spent early on in my PhD doing other things, or not having a clear direction and spending too much time making decisions, rather than making progress towards deadlines. Then again, I also spent a good month over the holidays spending more time with "life" than work, so on the whole, it is perhaps balance, though not at smaller time scales. In retrospect, I might have been able to maintain more balance throughout, but motivation is sometime difficult to maintain.[DELETED TEXT]

Thank you! 
Appendix 2. Sample journey plot

This journey plot was used at the beginning of an interview to focus the participant's attention on his/her experiences of the transition from completing the $\mathrm{PhD}$ to getting a first grant as Principal Investigator grant (McAlpine, 2016). It represents Romeos experience but has been redrawn to ensure anonymity. It formed the basis for the first part of the interview, in which the participant elaborated on the experiences noted.

\section{Journey plot}

Please draw the highs and lows of your experience of getting your first grant, from the time you completed your PhD until you received it. Please label the high and low points and insert any relevant dates.

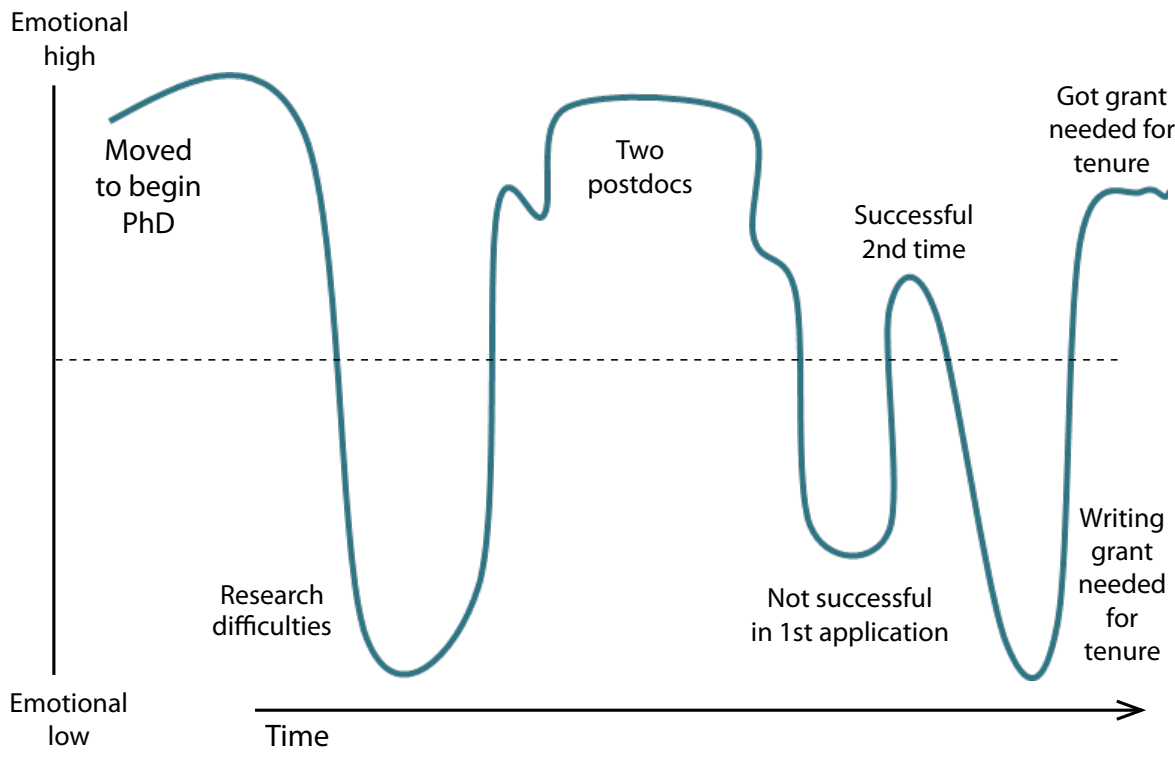


Appendix 3. Examples of researcher narrative constructions

Each of these examples draws on the narratives provided by one research participant who chose to call herself KS. The first is a more traditional researcher narrative reconstruction included in a paper, and the second one we developed for use on a website.

Example 1: Low-inference cameo included in a paper (McAlpine et al., 2014)

KS, 29, (SS) worked in various US NGOs before coming to the UK for a different experience. After getting a Master's at one university, she moved to another as a researcher on a short-term contract. She imagined doing a $\mathrm{PhD}$ since she enjoyed researching and realised she needed a doctorate to continue to do so. At the same time, she perceived her personal life on hold, and imagined returning to the US due to her close family relationships. Still, she recognized her developing UK academic networks might make career options in the US potentially challenging. She became a doctoral student in the same department, experiencing in some respects a loss of status but gaining a cohort of peers. She initially experienced challenging supervisory experiences and regretted not looking more broadly in choosing a program. Then, a critical illness in her family led her to suspend her doctoral work while she returned to the US for an extended period of time. Upon returning she took up the program with a new sense of purpose and completed her field work, though at the start of it another family illness temporarily disrupted her progress. After returning, she took on teaching and enjoys it, and is involved in a student journal while writing her thesis. She is largely committed to an academic career yet her desire for children is equally strong and she wonders how she can manage both. Having recently established a relationship, she recognises that, if it lasts, she will be planning her future around both hers and her partner's interests whether in the UK or the US. 


\section{Example 2: Formatting to show similarity in pattern of career decision-making over time (McAlpine, in press)}

Each of the three cameos has the same structure and demonstrates the same intentional pattern of doing the $\mathrm{PhD}$ in order to return to and be more effective in the professional field:

- alias, origin, prior work experience, personal relationships, reasons for doing the degree, initial career intentions (calibri)

- engagement in doctoral/academic work, changes in intentions during the move to post-PhD (times new roman)

- post-degree experience (arial narrow)

Daniel from Latin America, English second language, was an environmental professional and moved countries with his partner and child for the PhD. He intended to return to his profession afterwards and he felt the degree would provide important expertise and legitimacy. During the degree, he sought out opportunities to act as an advisor and consultant to develop his professional networks, but did not engage in publishing or presentations. As time passed, he increased this work to finance his studies, which extended time to completion. Before finishing the degree he and his family returned to his home country given visa issues. The consultancies he took on during his degree led to his being offered a professional position near the end of the degree in one of the organizations he had worked for as a consultant. He perceives the experience of the $\mathrm{PhD}$ as central to his present success. Not only did he expand his network of international experts that he continues to call on, he has also developed a way of thinking that is uncommon in his field - a particular questioning stance that people find attractive.
Shannon from North America was working as an educator when a colleague suggested she apply for a particular scholarship since a PhD would provide her with greater opportunity to achieve educational change, have policy impact. This meant leaving her close-knit family and moving countries.

Finding herself in a department in which few shared her

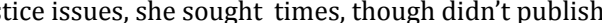
like-minded people elsewhere. since she wanted to finish her She didn't invest in presenting thesis. Near the end, she began or publishing. Instead, she engaged in pastoral work, since

she experienced the academic side of life as draining.

She put off making a decision about her future until completing the degree, at which point she sought a professional job combining research, policy and practice that could make an educational difference, close to where her family was. She found a senior administrative position in the headquarters of a school district near her family. However, the job was so 'full-on' that she had no time for a personal life despite wanting to be married and have children. Through a contact, she was offered a position in an educational nonprofit, first as vice-president and then president. In this position, she can shape the organisation and have better work-life balance.
Hannah, UK, raised a family while a healthcare professional and undertook the PhD in her home city. She had an interest in research related to her practice, imagining her future combining clinical practice and research. She recognised early on the need to overcome her naïvity, develop academic confidence and take charge of her project. She presented a number of job-seeking within an easy

She found a position in a non-university affiliated healthcare institution to build staff research capacity - she actually wrote her own job description. She knew it was necessary to publish in order to seek research funding and over a couple of years did so as well as sought relationships in a university since she lacked an academic environment and found her own research getting sidelined. Through her networking, she heard of and applied for a position in a university-affiliated healthcare institution, and the new position allows her to do the research she enjoyed (she has obtained funding) and build research capacity amongst her colleagues. She now aspires to employment further afield given her children are grown. commute. 


\section{Example 3: Alternate representation of individual narrative (excerpted) for use on website}

The following narrative represents KS' story told in a different way, three different strands of her life on the horizontal axis and time on the vertical axis to make her life searchable.

\section{Excerpt from KS Timelines: personal, work experience, future career - "my life - a yo-yo experience"}

PERSONAL: "re-location a pretty defining theme in my life"

Left close knit family in North America to move to the UK for a change

Personal life on hold

Saw doing $\mathrm{PhD}$ as decision to develop social and academic networks in UK

Critical illness in family; took leave and returned to North America for 6 months

Returned to the UK; coming back was such a relief; affirmed her decision to be there; longest she had lived anywhere since a child; hopefully pick up a husband and maybe a baby (biological imperative)

Further family illness while doing field work; managed to do both
WORK EXPERIENCE: "learned "not to have a solitary focus ... keep engaged in different things"

Worked after Bachelors' for a couple of years

Did Master's (finishing in 08)

2008-09: Moved university to be contract researcher; enjoyed collaborative nature of team

2009-10: her supervisor suggested doing $\mathrm{PhD}$, helped get funding on project; not necessarily her deep interest, but pragmatic

Started PhD; working alone; supervisor more distant; was it the right decision; trying to publish; helped by colleague from research contract; back-pedaling to catch up theoretically; remit to read (drowning in literature;

Very destabilised; lost momentum

2010-11: regained momentum; belonged to a cohort BUT ongoing concern re supervisor; helped by colleague; participating in the industry of producing words on paper - Are we actually moving forward? Need to create a path though readings

2011-12: field work in North America; extremely complicated to arrange; very isolating; cut off from academic context
CAREER THINKING:

Inspired, exhilarated by research

Growing UK academic network but losing North American one; felt 'under cover' as a researcher

Not sure what future held: postdoc or academic position in North America possibly

More aware of the challenge of getting an academic position; trying not to set heart on it; thinking of North America 